\title{
Mechanism of $\mathrm{T}$ cell mediated protection in newborn mice against a Chlamydia infection
}

\author{
Sukumar Pal ${ }^{*}$ and Luis M. de la Maza \\ Department of Pathology and Laboratory Medicine Medical Sciences, Room D440 University of \\ California, Irvine Irvine, CA 92697-4800 USA
}

\begin{abstract}
To determine the immune components needed for protection of newborn mice against Chlamydia muridarum, animals born to Chlamydia-immunized and to sham-immunized dams were infected intranasally with $C$. muridarum at 2 post-natal days. T-cells isolated from immunized or shamimmunized adult mice were adoptively transferred to newborn mice at the time of infection. Also, to establish what cytokines are involved in protection, IFN- $\gamma$ TNF- $\mathrm{a}$, IL-10, and IL-12 were passively transferred to newborn mice. To assess the Chlamydia burden in the lungs mice were euthanized at 12 post-natal days. When T-cells from immunized adult mice were transferred, mice born to and fed by immunized dams were significantly protected as evidenced by the reduced number of Chlamydia isolated from the lungs compared to mice born to and fed by shamimmunized dams. Transfer of IFN- $\gamma$ and TNF- $a$ also significantly reduced the number of Chlamydia in the lungs of mice born to immunized dams. Transfer of IL-10 or IL-12 did not result in a significant reduction of Chlamydia. In vitro T-cell proliferation data suggest that neonatal antigen presenting cells can present Chlamydia antigens to adult T-cells. In conclusion, maternal antibodies and Chlamydia specific T-cells or Th1 cytokines are required for protection of neonates against this pathogen.
\end{abstract}

\section{Keywords}

Neonatal immunity; Maternal antibodies; Chlamydia muridarum; Neonatal mouse model; Passive immunity

\section{INTRODUCTION}

Sexually transmitted infections are a major health problem in all countries. Chlamydia trachomatis is the most common sexually transmitted bacterial pathogen with approximately 100 million new cases reported each year [1]. Depending on the type of population studied, about 5 to 20 percent of women are positive for $C$. trachomatis and more than $50 \%$ of the

\footnotetext{
* Corresponding author: University of California, Irvine Department of Pathology and Laboratory Medicine Medical Science Building 1 Room \# D440 Irvine, CA 92697-4800 Phone: (949) 824-7450 Fax: (949) 824-2160 spal@ uci.edu.

Publisher's Disclaimer: This is a PDF file of an unedited manuscript that has been accepted for publication. As a service to our customers we are providing this early version of the manuscript. The manuscript will undergo copyediting, typesetting, and review of the resulting proof before it is published in its final citable form. Please note that during the production process errorsmaybe discovered which could affect the content, and all legal disclaimers that apply to the journal pertain.
} 
genital infections are asymptomatic [1]. If Chlamydia is not diagnosed and treated during pregnancy the babies could acquire the infection from their mothers. About one in three of the exposed infants develop inclusion conjunctivitis while approximately one in six are affected with pneumonia [2-4]. Infections of the genitourinary and gastrointestinal tracts of newborns have also been reported [3]. In addition to maternal transmission, in endemic area with a high incidence of trachoma about $10 \%$ infants are infected with $C$. trachomatis [5].

In the United States, it is estimated that nearly 3.5 million newborns are infected at the time of delivery and a significant number of them are asymptomatic [6, 7]. C. trachomatis pneumonitis is characterized by its insidious onset within the first three months of life. The clinical manifestations in neonates with Chlamydia sometimes are indistinguishable from infections with other respiratory pathogens such as respiratory syncytial virus, Ureaplasma urealyticum, cytomegalovirus and Pneumocystis carinii. Coinfection with other viruses which contribute to the severity of the original infection have been reported [8]. Neonatal chlamydial infections can be treated with antibiotics. However, in spite of antibiotic treatment, some neonates develop persistent infections $[4,6]$.

Neonates are highly susceptible to infections. Several factors, such as the immaturity of antigen presenting cells, impaired IgG isotype switching, deficiencies in complement and Th1-type cytokines, are thought to be responsible for the high susceptibility to infection [9-11]. So far, very few studies have attempted to understand the protective immune components of neonates in the presence of chlamydial maternal antibodies. This is probably due, at least in part, to the lack of appropriate animal models. Recently, we developed a mouse model of neonatal infection [12]. In this model, mice born to and fed by Chlamydia immunized dams, were infected at 2 postnatal days (PND). Using this model we showed that maternal antibodies from previously immunized dams were not sufficient to protect newborn mice against an i.n. challenge with Chlamydia [12]. In adult mice Th1 immunity is necessary to protect against $C$. trachomatis genital infections [13]. In addition, the IL-12/ IFN- $\gamma$ axis has been found to induce protection in newborn mice against a pulmonary infection [14].

Maternal antibodies have the ability to protect neonates whereas maternal T-cells cannot, because of the differences in tissue antigens, particularly HLA, between the mother and the fetus [15]. These differences raise the possibility of an attack on the fetus by maternal Tcells, but this danger is avoided by the absence of HLA antigen in the areas of placental contact [15]. Similarly, the risk that fetal lymphocytes will attack the mother is likewise low, because of the incompetence of fetal T-cells [15]. Since, neonates are born with immature Tand antigen presenting-cells (APC), the question arises whether neonates can utilize Chlamydia-specific adult T-cells to clear an infection. If they can, then it will be important to determine what kind of Th1 cytokine controls the infection. Here, to address this question, T-cells from Chlamydia immunized and sham-immunized adult inbreed mice were passively transferred to newborn mice before an i.n. challenge. In addition, T-cell derived Th1 effector cytokines, IFN- $\gamma$ and TNF- $a$, and modulating cytokines, IL-10 and IL-12, were passively transferred to newborn mice. Results of this study show that both T-cells, and T-cell derived Th1 effector cytokines, and maternal antibodies are required for protection against a chlamydial infection in neonates. 


\section{MATERIALS AND METHODS}

\section{1. Organisms}

The Nigg II strain of the $C$. trachomatis mouse pneumonitis MoPn (MoPn) biovar (now called Chlamydia muridarum) was obtained from the American Type Culture Collection (Manassas, VA) and was grown in HeLa-229 cells using Eagle's minimal essential medium [16-18]. Elementary bodies (EB) were purified and stored at $-70^{\circ} \mathrm{C}$ in sucrose phosphate glutamic acid buffer (SPG) [18].

\section{2. Animals}

Female and proven breeder male BALB/c $\left(\mathrm{H}-2^{\mathrm{d}}\right)$ mice were purchased from Charles River Laboratories (Wilmington, MA.). Groups of 3-4 week-old female BALB/c mice were intranasally (i.n.) immunized with $10^{4}$ inclusion forming units (IFU) of MoPn [17]. Control mice were sham-immunized with HeLa-229 cell extracts. For mating, six weeks after i.n. inoculation, four female mice were placed in the same cage with one male. Mice born from immunized or sham-immunized dams were inoculated i.n. with $10^{3} \mathrm{MoPn}$ IFU $\left(10 \times \operatorname{ID}_{50}\right)$ in $3 \mu \mathrm{l}$ of MEM-0 within the first $48 \mathrm{~h}$ of birth (2 PND) [12]. Prior to infection, newborn mice received intraperitoneally (i.p.) nylon wool enriched T-cells from immunized or sham immunized adult mice $\left(2.5 \times 10^{6}, 2.5 \times 10^{4}\right.$ or $2.5 \times 10^{4}$ cells per newborn mouse) [19]. To examine the role of cytokines, newborn animals were inoculated i.p. with one of the following in PBS (pH 7.2): IFN- $\gamma$ (40 ng), TNF-a (10 ng) [20], IL-10 (10 ng) [21] or IL-12 (50 ng) [22]. As controls, a group of newborn mice only received PBS (pH 7.2). At 10 days post infection (p.i.; 12 PND), newborn mice were euthanized, their lungs collected, homogenized in SPG and the number of MoPn IFU determined by infecting HeLa-229 cell monolayers. The animal protocol was approved by, the University of California Irvine, IACUC. All experiments were repeated.

\section{3. Collection of milk from mice}

Milk was collected from lactating dams at 12 PND as described [12, 23]. Briefly, to accumulate milk in the mammary glands, dams were separated from newborns mice for 4 to $5 \mathrm{~h}$. The dams were anesthetized with xylazine and ketamine and then inoculated i.p. with $1.5 \mathrm{U}$ of oxytocin (Sigma Chemicals; St. Louis, MO) in $150 \mu \mathrm{l}$ of PBS (pH 7.2). Whey samples from the milk were prepared by centrifugation and stored at $-70^{\circ} \mathrm{C}$.

\section{4. Immunoassays}

To determine the antibody levels in serum and whey samples an enzyme linked immunosorbent assay (ELISA) was performed [17]. At the time of euthanization, blood was collected from dams and newborn mice, while milk was collected from dams. The following class and subclass-specific antibodies were used: immunoglobulin $\mathrm{G}(\mathrm{IgG}), \operatorname{IgG1}, \operatorname{IgG} 2 \mathrm{a}$, IgG2b, IgG3, IgA, and IgM (Southern Biotechnology Associates, Inc., Birmingham, AL).

A T-cell lymphoproliferative assay (LPA) was performed using splenocytes as described [12]. Briefly, spleens from two to three newborn or adult mice were collected, teased, and enriched for T-cells by passing through nylon wool columns. After passage through a nylon wool column $90 \%$ of the cells were T-cells as determined with a fluorescence-labeled 
monoclonal antibody to CD3+ (GIBCO BRL, Grand Island, N.Y.). Enriched T-cells were counted and $10^{5}$ cells/well were placed in a 96-well plate. APC were prepared by treating splenocytes with 3300 rads using a ${ }^{137} \mathrm{Cs}$ irradiator. UV inactivated Chlamydia MoPn were added at a concentration of 10,1 and $0.1 \mathrm{~EB}$ to $1 \mathrm{APC}$.

To study accessory cell function each well received irradiated splenocytes $\left(1 \times 10^{5}\right)$, nylon wool enriched T-cells $\left(1 \times 10^{5}\right)$, and Concanavalin A ( $5 \mu \mathrm{g} / \mathrm{ml}$; Con A; Sigma). Negative control wells received medium instead Con A. Following $96 \mathrm{~h}$ of incubation, cell proliferation was measured by adding $1 \mu \mathrm{Ci}$ of $\left[\right.$ methyl $\left.{ }^{3} \mathrm{H}\right]$ ] thymidine per well. The mean counts per minute $(\mathrm{cpm})$ were determined from triplicate cultures.

\section{5. Organ culture}

At 12 PND, lungs were collected, homogenized in $2 \mathrm{ml}$ of SPG and dilutions inoculated in HeLa cell monolayers grown in 48 -well plates. Plates were incubated at $37^{\circ} \mathrm{C}$ and fixed with methanol at $30 \mathrm{~h} \mathrm{p}$,i. Inclusion s were detected by immuno-peroxidase staining using a pool of monoclonal antibodies to Chlamydia MoPn [12, 24].

\section{6. Statistics}

Statistical analyses were performed using the SigmaStat software. To determine the significance between the two treated groups on the yield of MoPn IFU, Mann-Whitney U test was employed. Two-tailed unpaired Student's $t$ test was used to determine significances between two sets of in vitro stimulation counts. Differences were considered significant when $\mathrm{P}$ values were $<0.05$.

\section{RESULTS}

\section{1. Measurement of Chlamydia antibody responses in dams and newborn mice}

Table 1 shows Chlamydia MoPn-specific antibody titers in dams and newborn mice at 12 PND. Overall, high IgG antibody titers in serum and milk were detected in the i.n. immunized dams. The IgG2a/IgG1 ratio in immunized dams sera was $4(25,600 / 6,400)$ indicative of a Th1 response. High levels of $\operatorname{IgA}(6,400)$ were also present in the serum samples of immunized dams. Low levels of MoPn specific antibody IgG titers $(1,600)$ were detected in the milk of immunized dams. Interestingly, no IgG1 and low levels of IgG2a antibody (800) were measured in the milk of immunized dams. As expected, high levels of $\operatorname{IgA}(12,800)$ were found in the milk. At 12 PND sham immunized dams, whose newborn mice had been infected, had low IgG antibody titers (100 to 400) in serum suggesting that their Chlamydia-inoculated newborn mice may have infected the dams.

High levels of antibody were detected in mice born to and fed by immunized dams (Table 1). At day 12 PND (D10 p. i.) newborn mice born to immunized dams had an IgG2a/IgG1 ratio of $4(25,600 / 6,400)$ and their serum IgA titer was 6,400. In contrast, mice born to sham immunized dams, and infected at 2 PND, had low IgG antibody titers ( $<100$ to 400$)$ in sera. 


\section{2. Adoptive transfer of T-cells to newborn mice}

To characterize the mechanisms of protection against a Chlamydia infection in newborn mice, T-cells from immunized, or sham immunized adult BALB/c mice, were adoptively transferred to 2 day-old newborn mice by i.p inoculation. Three different quantities of Tcells $2.5 \times 10^{6}, 2.5 \times 10^{5}$, and $2.5 \times 10^{4}$ per newborn, were adoptively transferred to mice born to immunized or sham immunized dams. A control group of newborn mice received RPMI-0. Following the adoptive transfer of T-cells, newborn mice were challenged i.n. with $10^{3} \mathrm{MoPn}$ IFU and were euthanized at 12 PND.

Serum IgG titers for each group of newborn mice at 12 PND are shown at the bottom of Figure 1. Mice born to immunized dams, that received $2.5 \times 10^{6}, 2.5 \times 10^{5}$ or $2.5 \times 10^{4} \mathrm{~T}$-cells from immunized adult mice, were significantly protected when compared to mice born to sham immunized dams receiving sham immune T-cells $(\mathrm{P}<0.05)$. Higher doses of T-cells $\left(2.5 \times 10^{6}\right.$ or $\left.2.5 \times 10^{5}\right)$ from MoPn immunized mice also protected newborn mice born to sham immune dams. This may be due to the over-reactive function of transferred T-cells from immunized adult mice. The role of T-cells in adoptive immunity was best observed with the $2.5 \times 10^{4} \mathrm{~T}$-cells dose. Significant level of protection $(\mathrm{P}<0.05)$ was seen in mice born to and fed by immunized dams receiving $2.5 \times 10^{4} \mathrm{~T}$-cells isolated from adult immunized. However, the same number of T-cells was not protective in mice born to sham-immunized dams. For example, the median (range) number of MoPn IFU recovered from the lungs of mice born to immunized dams, receiving $2.5 \times 10^{4} \mathrm{~T}$-cells from immunized mice, was 120 $(0-123,900)$. On the other hand, in mice born to sham immunized dams, receiving $2.5 \times 10^{4}$ T-cells from immunized or sham-immunized adult mice, the median number of MoPn IFU was $12,000(0-1,156,400)$ and $18,998(80-4,284,400)$, respectively. Control newborn mice, born to immunized dams or sham immunized dams, receiving RPMI-0 yielded a median number of 79,709 $(0-1,428,000)$ and 176,000 $(0-23,255,200)$ MoPn IFU from the lungs, respectively. Therefore, protection was associated with the presence of high levels of antibodies in newborn mice and transferred T-cells from immune adult mice.

\section{3. In vitro proliferative responses of T-cells from newborn mice}

To characterize the ability of newborn mice to present antigens to T-cells, uninfected mice born to immunized or sham-immunized dams were euthanized at 6 PND and their splenocytes were employed in an in vitro T-cell proliferation assay [12]. At the same time, MoPn immunized and sham immunized adult mice were euthanized and their splenocytes collected. T-cells from newborn or adult mice were stimulated with various concentration of MoPn EB in the presence of irradiated splenocytes used as APC [12]. T-cell proliferation was measured by [ ${ }^{3}$ Hthymidine] uptake after culturing the cells for four days (Figure 2).

When T-cells isolated from newborn mice were stimulated with MoPn EB in the presence of neonatal APC, no proliferation was observed. However, T-cells isolated from adult immunized mice and stimulated the same way, proliferated significantly when compared to T-cells isolated from adult sham immunized mice $(\mathrm{P}<0.05)$. This proliferation was Chlamydia-specific as there was no significant proliferation observed when T-cells isolated from adult sham immunized mice were stimulated with MoPn EB in the presence of APC from neonatal or sham immune adult splenocytes (Figure 2, plots f, g, h). For example, the 
average cpm (at 1:1 EB to APC) for APC from newborn mice and T-cells from adult immunized and sham immunized mice were $11,852 \pm 2,258$ and $243 \pm 87$, respectively $(\mathrm{P}>0.05)$. In comparison the average $\mathrm{cpm}$ at the same antigen concentration, for adult mice APC and T-cells from adult immunized and sham-immunized mice were 9,865 4,071 and $200 \pm 100$, respectively ( $\mathrm{P}<0.05$; Figure 2 , plots $\mathrm{b}, \mathrm{f}, \mathrm{d}, \mathrm{h}$ ). These results suggest that neonatal APC can present Chlamydia antigens to T-cells from adult MoPn immunized mice.

To analyze the ability of newborn splenocytes to support $\mathrm{T}$ cell growth, newborn mice were euthanized at 6 PND and accessory cells were prepared by irradiating splenocytes as described above. Irradiated splenocytes were tested for their ability to function as accessory cells, in an in vitro T-cell proliferation assay, using Con A as a T-cell stimulant (Figure 3). These experiments were conducted based on the previous observation that Con A stimulated T-cells needed accessory cells for sustaining in vitro growth [25]. When T-cells from newborn mice were stimulated with Con A in the presence of newborn mice accessory cells, a low level of proliferation was observed. This indicates that either splenocyes from newborn mice could not function as accessory cells or that Con A could not stimulate newborn mice T-cells (Figure 3a).

When T-cells from newborn or adult mice were stimulated with Con A in the presence of accessory cells prepared from either newborn or adult mice significant proliferation was observed in all groups (Figure 3, plots b, c, d). The highest level of proliferation was observed with T- and accessory cells from adult mice. For example, when T- and accessory cells from newborn mice were stimulated with Con A the mean cpm was 2,304+494 (Figure $3 a)$. In contrast, when T-cells from newborn mice and accessory cells from adult mice, or the reverse ( $\mathrm{T}$-cells from adult mice and accessory cells from newborn mice), were stimulated with Con A, the mean cpm increased from 12,295+1,799 to 20,449+3,048 (Figure 3 b, c). In addition, when both $\mathrm{T}$ - and accessory cells from adult mice were used, the mean cpm was $36,064+10,518$ (Figure 3d). These results imply that neonatal splenocytes can function as accessory cells and support T-cell growth.

\section{4. Passive transfer of cytokines to newborn mice}

Next, we asked whether T-cell derived effectors or modulating cytokines can help to clear a respiratory Chlamydia infection in newborn mice (Figure 4). IL-10 and IL-12 were tested as modulating cytokines and IFN- $\gamma$ and TNF-a as effector cytokines. Following a passive transfer of the cytokine to mice born to immunized or sham immunized dams, newborn mice were infected with MoPn at 2 PND. As a negative control, newborn mice received PBS. The antibody titers of each group of newborn mice at 12 PND are shown at the bottom of Figure 4. Mice born to immunized dams receiving IFN- $\gamma$ or TNF-a had significantly reduced Chlamydia burdens in their lungs compared to the control newborn mice receiving PBS $(\mathrm{P}<0.05$; Figure 4). The median (range) number of IFU recovered from the lungs of mice born to immunized dams receiving IFN- $\gamma$ or TNF- $a$, were 2,189 (0-520,380), and 22,000 $(0-338,660)$, respectively. In contrast the mice born to immunized dams inoculated with PBS yielded 79,709 $(0-1,428,000)$ IFU $(\mathrm{P}<0.05)$. Furthermore, the median number of IFU recovered from the lungs of mice born to sham immunized dams receiving IFN- $\gamma$ TNF- $a$, and PBS were 64,240 (0-1,670,400), 488,400 (0-8,518,600), and 85,904 (0-40,129,400), 
respectively. Therefore, Th1 cytokines can help newborn mice to control a chlamydial respiratory infection.

To assess if modulating cytokines were involved in protection, IL-10 and IL-12 were passively transferred to newborn mice. IL-10 and IL-12 did not reduced the Chlamydia burden in the lungs of mice born to immunized or sham immunized dams (Figure 4). In all passive cytokine transfer experiments a reduced Chlamydia burden was noticed in the lungs of newborn mice that had high levels of Chlamydia-specific antibodies and received IFN- $\gamma$ or TNF-a.

\section{DISCUSSION}

Previously we had shown that newborn mice born to and fed by $C$. muridarum immunized dams were not protected against an i.n. challenge with MoPn [12]. Although dams had high levels of Chlamydia-specific antibodies in serum and milk, newborn mice could not clear the Chlamydia infection following an i.n. challenge. Thus, we postulated that, in addition to maternal antibodies, newborn mice needed T-cells or T-cell secreting cytokine(s) to clear the infection [12]. Here, we showed that in addition to Chlamydia-specific maternal antibodies, T-cells from MoPn immunized adult mice, or Th1 cytokines such as IFN- $\gamma$ or TNF-a, are capable of reducing the Chlamydia burden in the lungs of newborn mice. In vitro $\mathrm{T}$ cell proliferation assays support the notion that newborn mice APC are capable of presenting antigen as well as functioning as accessory cells to T-cells from adult mice.

Several investigators have shown that in naïve adult female mice, passive transfer of Chlamydia-specific T-cells, or Th1 lymphocyte clones, can clear chlamydial genital infections [26-28]. Here we showed that mice, born to and fed by immunized or sham immunized dams, that received $2.5 \times 10^{6}$ or $2.5 \times 10^{5} \mathrm{~T}$-cells from immunized adult mice, have a significantly reduced Chlamydia burden in their lungs. However, protection was not observed in newborns of sham-immunized mice that received less T-cells $\left(2.5 \times 10^{4}\right)$ from immunized adult mice. In this group, the protection was only observed in newborn mice born to and fed by immunized dams. These results are not surprising considering that CD4+ T-cells and B-cells or antibodies, were shown to be important for the clearance of chlamydial genital infections in adult immunized mice [29-31]. Since at risk babies are born from an infected mother, they will have maternal antibodies in their sera. Thus, neonates born from an infected mother need limited help from T-cells to synergistically work to reduce the Chlamydia burden. The importance of both maternal antibodies and T-cells has also been established for HSV infections in newborn mice. Kohl et al. (1982) showed that neonate mice can survive a lethal HSV infection when interferon, antibody to HSV, and leukocytes were, simultaneously, passively transferred [32].

Antibody dependent cellular cytotoxicity (ADCC) has been shown to be an effector mechanism for killing Chlamydia in mature adult hosts [33]. Since neonates are born with immature cellular immune system, ADCC may not function well in the presence of maternal antibodies. However, this condition changes in an experimental condition when newborn mice adoptively receive immune cells from adult mice. Adoptively transferred adult T-cells and maternal antibodies may work together to clear a Chlamydia infection by ADCC. This 
may explain why significant protection was observed in newborn mice, born to and fed by immune dams that received mature T-cells from MoPn-immunized or sham-immunized mice. Similar level of protection by ADCC was reported in an experimental HSV infection. Newborn mice receiving both anti-HSV antibodies and leukocytes from humans were able to clear a lethal HSV infection [34, 35].

Passive transfer of Th1 effector cytokines such as, IFN- $\gamma$ or TNF-a resulted in significant protection in newborn mice. These observations are in agreement with previous findings in which passively transferred IFN- $\gamma$ or TNF- $\alpha$ cleared a chlamydial infection in adult mice [36-38]. Between the two effector-cytokines, IFN- $\gamma$ is more desirable since excessive TNFa production may deter neonatal development [39]. It is not well understood how TNF-a clears a Chlamydia infection, although several mechanisms such as, up regulation of IFN- $\beta$, NK cells or neutrophils, have been proposed [38]. Clearance of Chlamydia by IFN- $\gamma$ has been well studied and three mechanisms have been proposed: 1) inhibition of indoleamine 2 , 3-dioxygenase (IDO), 2) up-regulation of nitric oxide synthase, and 3) down-regulation of transferrin receptors for iron transport [40]. Recently, in mouse epithelial cells, p47 GTPases but not IDO, were shown to be involved in killing MoPn [41]. It will be important to know what kind of killing mechanisms against Chlamydia are active in the neonatal environment in the presence of IFN- $\gamma$.

In these studies, Th modulating cytokines, specifically IL-12 and IL-10, were not able to induce significant protection in newborn mice suggesting that they were not capable of inducing Th1 cytokines in a neonatal environment. However, Jupelli et al. [14], using IL-12p35-/- knockout mice, showed that IL-12 played an important role in the clearance of Chlamydia in newborn mice. In their study $100 \%$ mortality was observed in IL-12p35-/newborn mice by day 17 p.i. following an intranasal challenge at 1 PND. The differences with our findings may be due to: 1) the mouse strain used (BALB/c versus C57BL/6); 2) length of time animals were studied (12 PND versus $18 \mathrm{PND}$ ), and 3 ) nature of the experiment (passive transfer of recombinant IL-12 versus IL-12/p35-/- mice). Although IL-10 has been shown to be a protective cytokine in neonatal mice against a lethal group B streptococcal infection $[42,43]$, in our study no protection was observed in mice. This observation is not surprising considering that adult IL-10 knockout mice showed enhanced Th1-like protective immunity following a MoPn lung infection [44]. These results suggest that modulating cytokines may not be effective in reducing Chlamydia burden in newborn mice.

When APC and T-cells from newborn mice were used in a LPA, no proliferation was observed probably because neonatal splenocytes are immature. Other investigators have observed this phenomenon [45]. However, when APC from newborn mice were cultured with T-cells from adult immunized mice in the presence of Chlamydia EB, APC from newborn mice were able to present antigen to Chlamydia-specific adult mice T-cells. This suggests that newborn APC are not as immunological immature as originally thought. This in vitro observation also supports our in vivo $\mathrm{T}$ cell transfer experiments where T-cells from immunized adult mice were passively transferred to newborn mice. Thus, it is possible that, following the passive transfer of T-cells, APC of newborn mice were able to present Chlamydia antigen(s) to Chlamydia-specific adult T-cells and hence, reduce the Chlamydia 
burden from the lungs. Similarly, in vitro accessory cell function observations support the in vivo $\mathrm{T}$ cell transfer data. In both cases, APC from newborn mice were able to sustain adult T cell growth in vitro and in vivo when mixed with adult T-cells. Alternatively, it is possible that adult T-cells, when they are together in vivo or in vitro, can induce neonatal APC from a non-responsive to a responsive state. Further studies are needed to elucidate the role of adult T-cells in maturing neonatal cells.

In conclusion, our in vivo results confirm that, in addition to maternal antibodies, Th1 effector cytokines such as IFN- $\gamma$ or TNF- $a$ are required to clear a chlamydial infection in neonates. Furthermore, this is the first time that neonatal APC were shown to be capable of an adult-like function in the presence of adult T-cells. Thus, it seems that, under certain conditions, neonatal APC can be switched from immature to functional immunological mature cells.

\section{ACKNOWLEDGMENTS}

This work was supported by Public Health Service grants AI-64853 to S. Pal and AI-32248 to L. M. de la Maza, from the National Institute of Allergy and Infectious Diseases.

\section{REFERENCES}

[1]. Chlamydia screening among sexually active young female enrollees of health plans--United States, 2000-2007. MMWR Morb Mortal Wkly Rep. 2009; 58:362-365. [PubMed: 19373196]

[2]. Numazaki K, Asanuma H, Niida Y. Chlamydia trachomatis infection in early neonatal period. BMC Infect Dis. 2003; 3:2. [PubMed: 12697048]

[3]. Schachter J, Caldwell HD. Chlamydiae. Annu Rev Microbiol. 1980; 34:285-309. [PubMed: 7002026]

[4]. Persson K, Ronnerstam R, Svanberg L, Polberger S. Neonatal chlamydial conjunctivitis. Arch Dis Child. 1986; 61:565-568. [PubMed: 3729525]

[5]. Brunham RC, Laga M, Simonsen JN, Cameron DW, Peeling R, McDowell J, Pamba H, NdinyaAchola JO, Maitha G, Plummer FA. The prevalence of Chlamydia trachomatis infection among mothers of children with trachoma. Am J Epidemiol. 1990; 132:946-952. [PubMed: 2239909]

[6]. Darville T. Chlamydia trachomatis infections in neonates and young children. Semin Pediatr Infect Dis. 2005; 16:235-244. [PubMed: 16210104]

[7]. Darougar S. Prevalence of Chlamydia trachomatis infections in pregnant women and neonates. Ann N Y Acad Sci. 1988; 549:24-30. [PubMed: 3228254]

[8]. Dereli D, Coker M, Ertem E, Serter D, Tanac R, Tez E. Chlamydial infection in infants. J Trop Pediatr. 1996; 42:233-236. [PubMed: 8816036]

[9]. Levy O. Innate immunity of the newborn: basic mechanisms and clinical correlates. Nat Rev Immunol. 2007; 7:379-390. [PubMed: 17457344]

[10]. Forsthuber T, Yip HC, Lehmann PV. Induction of TH1 and TH2 immunity in neonatal mice. Science. 1996; 271:1728-1730. [PubMed: 8596934]

[11]. Ridge JP, Fuchs EJ, Matzinger P. Neonatal tolerance revisited: turning on newborn T cells with dendritic cells. Science. 1996; 271:1723-1726. [PubMed: 8596932]

[12]. Pal S, Tatarenkova O, de la Maza LM. Maternal immunity partially protects newborn mice against a Chlamydia trachomatis intranasal challenge. J Reprod Immunol. 2010; 86:151-157. [PubMed: 20554327]

[13]. Morrison RP, Caldwell HD. Immunity to murine chlamydial genital infection. Infect Immun. 2002; 70:2741-2751. [PubMed: 12010958]

[14]. Jupelli M, Selby DM, Guentzel MN, Chambers JP, Forsthuber TG, Zhong G, Murthy AK, Arulanandam BP. The contribution of interleukin-12/interferon-gamma axis in protection against 
neonatal pulmonary Chlamydia muridarum challenge. Journal of interferon \& cytokine research. 2010; 30:407-415. [PubMed: 20187773]

[15]. Zinkernagel RM. Maternal antibodies, childhood infections, and autoimmune diseases. N Engl J Med. 2001; 345:1331-1335. [PubMed: 11794153]

[16]. Nigg C. An Unidentified Virus Which Produces Pneumonia and Systemic Infection in Mice. Science. 1942; 95:49-50.

[17]. Pal S, Fielder TJ, Peterson EM, de la Maza LM. Protection against infertility in a BALB/c mouse salpingitis model by intranasal immunization with the mouse pneumonitis biovar of Chlamydia trachomatis. Infect Immun. 1994; 62:3354-3362. [PubMed: 8039906]

[18]. Caldwell HD, Kromhout J, Schachter J. Purification and partial characterization of the major outer membrane protein of Chlamydia trachomatis. Infect Immun. 1981; 31:1161-1176. [PubMed: 7228399]

[19]. You D, Ripple M, Balakrishna S, Troxclair D, Sandquist D, Ding L, Ahlert TA, Cormier SA. Inchoate CD8+ T cell responses in neonatal mice permit influenza-induced persistent pulmonary dysfunction. J Immunol. 2008; 181:3486-3494. [PubMed: 18714021]

[20]. Campbell IL, Oxbrow L, Harrison LC. Reduction in insulitis following administration of IFNgamma and TNF-alpha in the NOD mouse. Journal of autoimmunity. 1991; 4:249-262. [PubMed: 1909136]

[21]. Davidson NJ, Hudak SA, Lesley RE, Menon S, Leach MW, Rennick DM. IL-12, but not IFNgamma, plays a major role in sustaining the chronic phase of colitis in IL-10-deficient mice. J Immunol. 1998; 161:3143-3149. [PubMed: 9743382]

[22]. Lee HH, Hoeman CM, Hardaway JC, Guloglu FB, Ellis JS, Jain R, Divekar R, Tartar DM, Haymaker CL, Zaghouani H. Delayed maturation of an IL-12-producing dendritic cell subset explains the early Th2 bias in neonatal immunity. J Exp Med. 2008; 205:2269-2280. [PubMed: 18762566]

[23]. Parr EL, Bozzola JJ, Parr MB. Purification and measurement of secretory IgA in mouse milk. J Immunol Methods. 1995; 180:147-157. [PubMed: 7714330]

[24]. Pal S, Davis HL, Peterson EM, de la Maza LM. Immunization with the Chlamydia trachomatis mouse pneumonitis major outer membrane protein by use of $\mathrm{CpG}$ oligodeoxynucleotides as an adjuvant induces a protective immune response against an intranasal chlamydial challenge. Infect Immun. 2002; 70:4812-4817. [PubMed: 12183524]

[25]. Palacios R. Concanavalin A triggers T lymphocytes by directly interacting with their receptors for activation. J Immunol. 1982; 128:337-342. [PubMed: 6459373]

[26]. Hawkins RA, Rank RG, Kelly KA. A Chlamydia trachomatis-specific Th2 clone does not provide protection against a genital infection and displays reduced trafficking to the infected genital mucosa. Infect Immun. 2002; 70:5132-5139. [PubMed: 12183563]

[27]. Igietseme JU, Ramsey KH, Magee DM, Williams DM, Kincy TJ, Rank RG. Resolution of murine chlamydial genital infection by the adoptive transfer of a biovar-specific, Th1 lymphocyte clone. Reg Immunol. 1993; 5:317-324. [PubMed: 8068534]

[28]. Li W, Murthy AK, Guentzel MN, Seshu J, Forsthuber TG, Zhong G, Arulanandam BP. Antigenspecific CD4+ T cells produce sufficient IFN-gamma to mediate robust protective immunity against genital Chlamydia muridarum infection. J Immunol. 2008; 180:3375-3382. [PubMed: 18292563]

[29]. Su H, Feilzer K, Caldwell HD, Morrison RP. Chlamydia trachomatis genital tract infection of antibody-deficient gene knockout mice. Infect Immun. 1997; 65:1993-1999. [PubMed: 9169723]

[30]. Morrison SG, Su H, Caldwell HD, Morrison RP. Immunity to murine Chlamydia trachomatis genital tract reinfection involves B cells and CD4(+) T cells but not CD8(+) T cells. Infect Immun. 2000; 68:6979-6987. [PubMed: 11083822]

[31]. Farris CM, Morrison SG, Morrison RP. CD4+ T cells and antibody are required for optimal major outer membrane protein vaccine-induced immunity to Chlamydia muridarum genital infection. Infect Immun. 2010; 78:4374-4383. [PubMed: 20660610]

[32]. Kohl S, Loo LS, Greenberg SB. Protection of newborn mice from a lethal herpes simplex virus infection by human interferon, antibody, and leukocytes. J Immunol. 1982; 128:1107-1111. [PubMed: 6173420] 
[33]. Moore T, Ananaba GA, Bolier J, Bowers S, Belay T, Eko FO, Igietseme JU. Fc receptor regulation of protective immunity against Chlamydia trachomatis. Immunology. 2002; 105:213221. [PubMed: 11872097]

[34]. Kohl S, Loo LS. Protection of neonatal mice against herpes simplex virus infection: probable in vivo antibody-dependent cellular cytotoxicity. J Immunol. 1982; 129:370-376. [PubMed: 6282968]

[35]. Koren HS, Amos DB, Kim YB. Natural killing and antibody-dependent cellular cytotoxicity are independent immune functions in the Minnesota miniature swine. Proc Natl Acad Sci U S A. 1978; 75:5127-5131. [PubMed: 154104]

[36]. de la Maza MA, de la Maza LM. A new computer model for estimating the impact of vaccination protocols and its application to the study of Chlamydia trachomatis genital infections. Vaccine. 1995; 13:119-127. [PubMed: 7762268]

[37]. Zhong GM, Peterson EM, Czarniecki CW, Schreiber RD, de la Maza LM. Role of endogenous gamma interferon in host defense against Chlamydia trachomatis infections. Infect Immun. 1989; 57:152-157. [PubMed: 2491833]

[38]. Williams DM, Magee DM, Bonewald LF, Smith JG, Bleicker CA, Byrne GI, Schachter J. A role in vivo for tumor necrosis factor alpha in host defense against Chlamydia trachomatis. Infect Immun. 1990; 58:1572-1576. [PubMed: 2341167]

[39]. Marodi L. Neonatal innate immunity to infectious agents. Infect Immun. 2006; 74:1999-2006. [PubMed: 16552028]

[40]. Beatty WL, Byrne GI, Morrison RP. Morphologic and antigenic characterization of interferon gamma-mediated persistent Chlamydia trachomatis infection in vitro. Proc Natl Acad Sci U S A. 1993; 90:3998-4002. [PubMed: 8387206]

[41]. Nelson DE, Virok DP, Wood H, Roshick C, Johnson RM, Whitmire WM, Crane DD, SteeleMortimer O, Kari L, McClarty G, Caldwell HD. Chlamydial IFN-gamma immune evasion is linked to host infection tropism. Proc Natl Acad Sci U S A. 2005; 102:10658-10663. [PubMed: 16020528]

[42]. Cusumano V, Genovese F, Mancuso G, Carbone M, Fera MT, Teti G. Interleukin-10 protects neonatal mice from lethal group B streptococcal infection. Infect Immun. 1996; 64:2850-2852. [PubMed: 8698523]

[43]. Nicoletti F, Mancuso G, Ciliberti FA, Beninati C, Carbone M, Franco S, Cusumano V. Endotoxin-induced lethality in neonatal mice is counteracted by interleukin-10 and exacerbated by anti-IL-10. Clin Diagn Lab Immunol. 1997; 4:607-610. [PubMed: 9302214]

[44]. Yang X, Gartner J, Zhu L, Wang S, Brunham RC. IL-10 gene knockout mice show enhanced Th1-like protective immunity and absent granuloma formation following Chlamydia trachomatis lung infection. J Immunol. 1999; 162:1010-1017. [PubMed: 9916727]

[45]. Zaghouani H, Hoeman CM, Adkins B. Neonatal immunity: faulty T-helpers and the shortcomings of dendritic cells. Trends Immunol. 2009; 30:585-591. [PubMed: 19846341] 


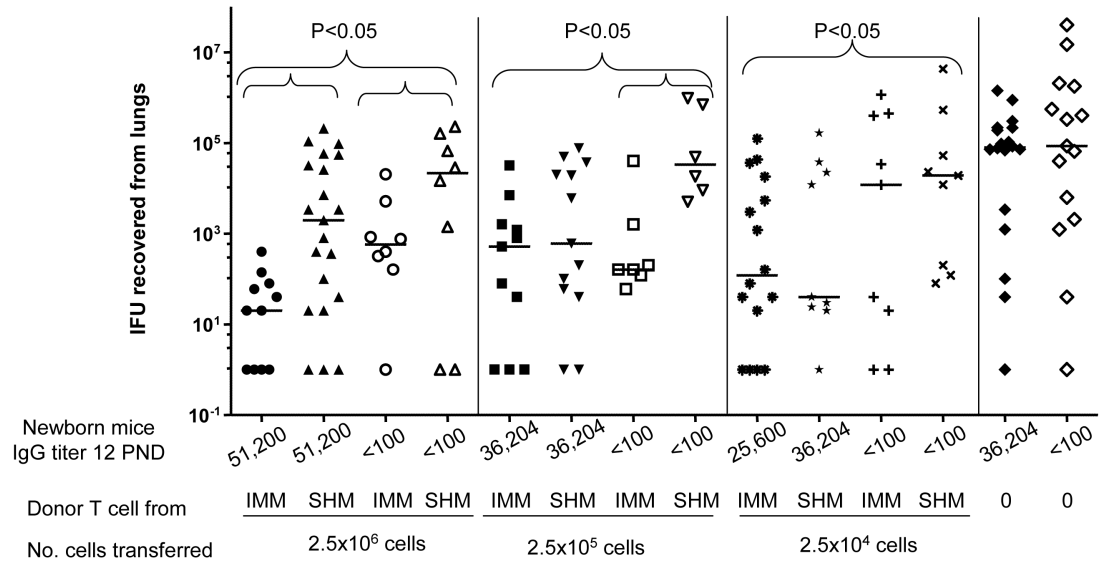

Groups

Figure 1. Adoptive transfer of T-cells from immunized or sham-immunized adult mice to 2 dayold newborn mice

Newborn mice received i.p. various amounts of adult T-cells $\left(2.5 \times 10^{6}, 2.5 \times 10^{5}\right.$, and $2.5 \times 10^{4}$ ) from immunized adult (IMM) or sham immunized adult mice (SHM) at 2 PND before an i.n. challenge with MoPn. Newborn mice were euthanized at 12 PND. Horizontal bars represent median number of Chlamydia IFU recovered from each group. Antibody titers, for each group of newborn mice at 12 PND, are shown at the bottom of the figure. 


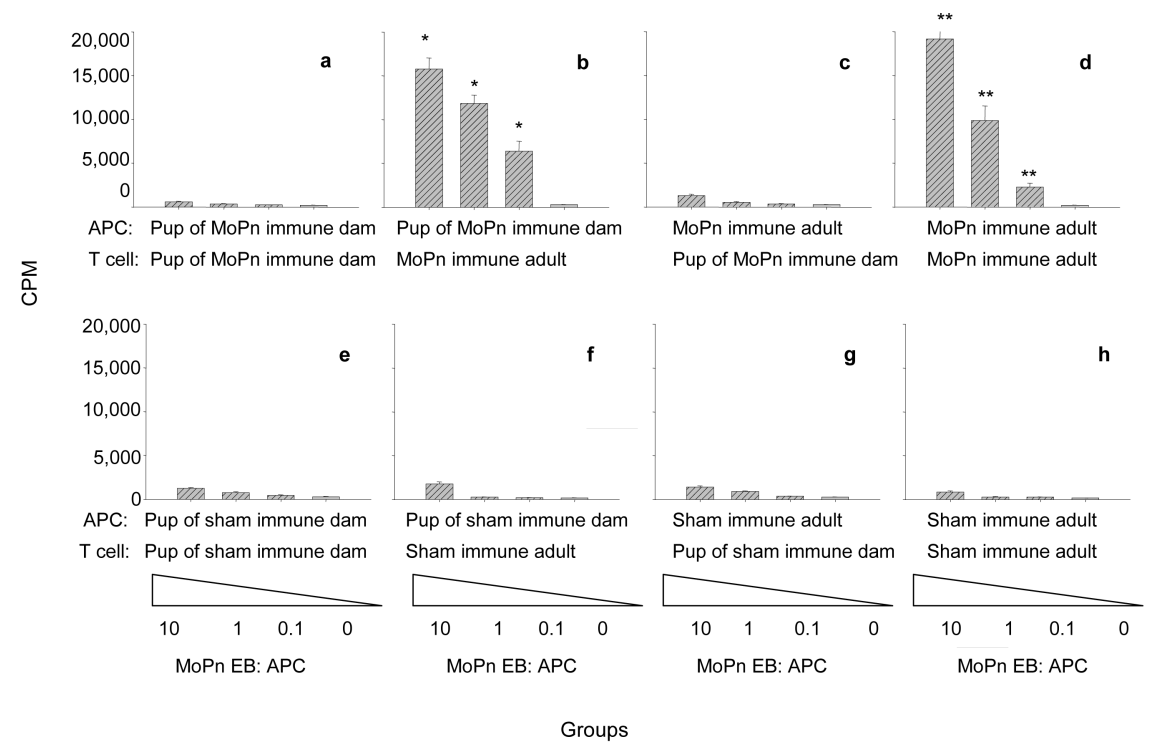

Figure 2. Antigen presentation by newborn splenocytes to adult T-cells

T-cells from newborn and adult mice were stimulated with MoPn EB in the presence of adult or newborn APC. The results are expressed as mean cpm derived from triplicate cultures. Plots $2 \mathrm{a}$ to $2 \mathrm{e}$ represent newborn mice born to MoPn immunized dams and plots $2 \mathrm{e}$ to $2 \mathrm{~g}$ correspond to newborn mice born to sham-immunized dams. * Significant by the Student's $t$ test $(\mathrm{P}<0.05)$ compared to $\mathrm{T}$ cell cultures of sham immunized adult mice with APC from newborn mice born to sham immunized dams. ** Significant by the Student's $t$ test $(\mathrm{P}<0.05)$ compared to $\mathrm{T}$ cell cultures of sham immunized adult mice with APC from sham immunized adult mice. 

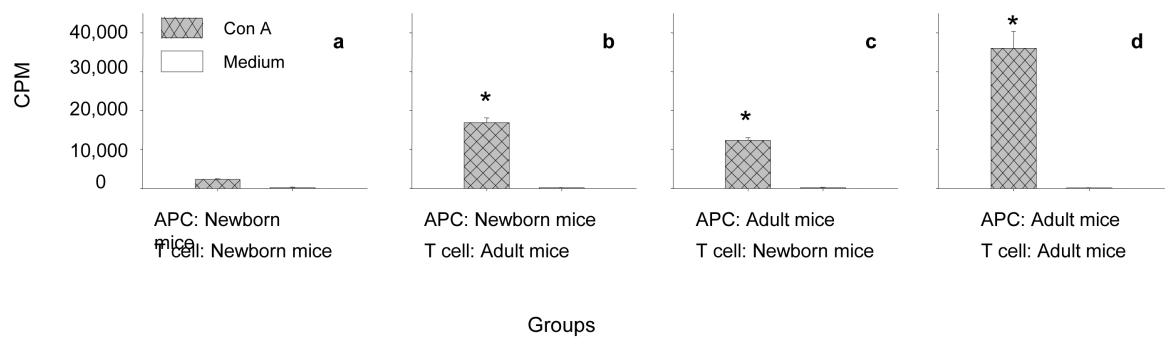

Figure 3. Accessory cell function of newborn splenocytes to adult T-cells

T-cells from newborn and adult mice were stimulated with Con $\mathrm{A}$ in the presence of adult or newborn APC. The results are expressed as mean cpm from triplicate cultures. * Significant by the Student's $t(\mathrm{P}<0.05)$ test when compared to the T-cell cultures with newborn T cells and accessory cells from newborn mice. 


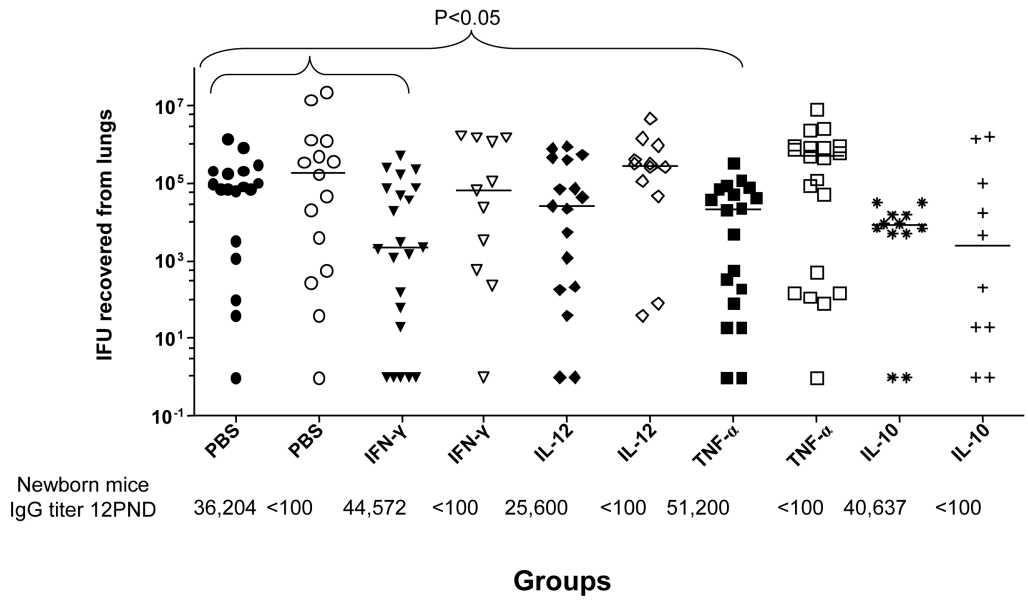

Figure 4. Passive transfer of cytokines to 2 day-old newborn mice

Newborn mice received various cytokines i.p. at 2 PND before an i.n. challenge. Following the challenge the newborn mice were euthanized at 12 PND. Filled symbols represent newborn mice born to immunized dams while open symbols represent newborn mice born to sham immunized dams. Horizontal bars represent median number of Chlamydia IFU recovered from each group. Antibody titers for each group of newborn mice at 12 PND are shown at the bottom of the figure. 


\section{Table 1}

Antibody titer of dams and newborn mice at 12 PND following an i.n. infection.

\begin{tabular}{lcccccccc}
\hline & & \multicolumn{7}{c}{ Anti-MoPn ELISA titer } \\
\cline { 2 - 8 } Mouse type & Sample & IgG & IgG1 & IgG2a & IgG2b & IgG3 & IgA & IgM \\
\hline MoPn immunized dam & Sera & 51,200 & 6,400 & 25,600 & 25,600 & 1,600 & 6,400 & 100 \\
& Whey & 1,600 & $<100$ & 800 & 800 & 100 & 12,800 & $<100$ \\
Sham immunized dam & Sera & 200 & 100 & $<100$ & 100 & $<100$ & 400 & 100 \\
& Whey & $<100$ & $<100$ & $<100$ & $<100$ & $<100$ & 200 & 100 \\
$\begin{array}{c}\text { Newborn mice born to MoPn } \\
\text { immunized dam }\end{array}$ & Sera & 51,200 & 6,400 & 25,600 & 25,600 & 1,600 & 6,400 & 100 \\
$\begin{array}{c}\text { Newborn mice born to sham } \\
\text { immunized dam }\end{array}$ & Sera & 200 & 100 & $<100$ & 100 & $<100$ & 400 & 200 \\
\hline
\end{tabular}

